The classical theory about effects of high residential density is "negative," stating that high density produces negative social attitudes and undesirable behaviors. Yet empirical research usually finds density only weakly related to individuals' attitudes and behavior. A survey was conducted in Baltimore for three purposes: to test "negative" hypotheses for new dependent variables; to determine if negative density effects appear only when certain "buffers" are weak; and to test hypotheses about "positive" effects of density. Results show that large population size and feelings that an area is overpopulated produce frustrations about the environment. Objective density has some negative and positive effects, but it is less important than population size, subjective appraisal of population, and population composition. Compared to prior research, the special contributions of the Baltimore study are examination of (1) population size, (2) "positive" consequences of high density and large size, and (3) effects in three distinct residential areas.

\title{
CONSEQUENCES OF POPULATION DENSITY AND SIZE
}

LOIS M. VERBRUGGE

University of Michigan

RALPH B. TAYLOR

Johns Hopkins University

The classical model of density effects claims that high density causes emotional stress and that this stress produces negative social affect and attitudes toward other people. These hypotheses were suggested by Simmel (1971) and American sociologists of

\footnotetext{
AUTHORS' NOTE: This research was supported by NIMH Grant I R03 MH27643 and by the University of Michigan Rackham School of Graduate Studies. The authors thank the Department of Social Relations and the Center for Metropolitan Planning and Research, both of Johns Hopkins University. for supporting services; Hank Becker of the Survey Research Unit, Johns Hopkins University, for assistance in designing the sample; graduate students who helped in the study's design, data collection, and analysis; and colleagues who commented on versions of this article.
} 
the "Chicago School" (Wirth, 1938). Simmel speculated that constant exposure to other people is stressful. To accommodate continual stimulation, urban residents adopt a blasé reserved attitude or hostility toward others. Wirth also emphasized attitudinal and effective responses to high density, focusing on individual reactions rather than social structural ones. ${ }^{1}$ Wirth thought that three aspects of urban life have profound consequences on humans: population size, population density, and population heterogeneity. He suggested that high urban density fosters a sense of competition, reserve, loneliness, and irritation (1938: 15-16). Milgram (1970) and Fischer (1972) have reformulated Simmel and Wirth's thought with greater precision, but without fundamental changes in the hypotheses.

Recent sociological research has deviated from the classical model in several ways. First, although Simmel and Wirth discussed individuals' reactions to density, sociologists have often used areas as units of anlaysis (Choldin and Roncek, 1976; Galle et al., 1972; Schmitt, 1966; Winsborough, 1965). Individual-level studies are relatively rare (Baldassare, 1975; Booth, 1976; Felson and Solaún, 1975; Loring, 1956a, 1956b; Mitchell, 1971). Second, although Simmel and Wirth considered affective and attitudinal responses, many studies instead use behaviors as the dependent variables. For example, areal analyses have used rates of mortality, tuberculosis, suicide, mental hospital admission, and juvenile delinquency. The implicit claim is that negative attitudes induce negative ("pathological") behaviors. Third, a great variety of density measures have been used. Some are ratios of population to area (consistent with Simmel and Wirth's perspective). Others compare population to a structural unit (e.g., persons per room, or a room's deficit measure; Booth, 1976), or compare structures to area. Fourth, Simmel and Wirth were mainly interested in densities encountered in public places, not in residential settings, yet most sociological research considers effects of residential density. The spatial units vary greatly among studies; common ones are the household, block, census tract, and city. Fifth, empirical research has focused on associations between density and attitudes or behavior. The intervening processes (i.e., stress) 
that link density to those responses are assumed to occur but have not been measured. ${ }^{2}$

Despite all the variations just noted, the model of negative effects is not strongly supported by empirical research. When socioeconomic and demographic characteristics are controlled, few strong effects between density and social attitudes or behavior appear. ${ }^{3}$ Does population density have no important effects on individuals, or are high-density communities organized to blunt negative effects of high density (Day and Day, 1973)? Apart from macro organization, do individuals adapt to high density and thereby blunt negative effects, or has research failed to identify the attitudes and behaviors which are indeed influenced by population density?

Two possibilities must be examined before making conclusions about density effects: (1) Negative effects of high density may occur, but only under certain conditions. For example, when high-density cities are not structured to accommodate high population flows and demands, people may be frustrated and behave more aggressively than in well-structured cities (Jacobs, 1961). When individuals are newcomers to a high-density area or when they value privacy, they may be more upset and hostile than long-term residents and people with few privacy needs. (2) Variations in density may influence attitudes and behaviors not identified in prior research. Research has focused on "pathological" behaviors (in areal data) and interpersonal conflicts (in individual data). ${ }^{4}$ It is not always easy to understand how density actually influences these behaviors. The intervening processes are probably complex and often are not measured. If one wants to find density effects that are statistically significant and also interpretable, one needs to idertify in advance social attitudes and behaviors that are plausibly and "closely" related to density.

What are some likely consequences of high population density? As population density increases, some environmental resources diminish. Space for activities and easy movement decreases; privacy and quiet decrease; property control and predictability of local events decrease. In general, high density spurs competition 
for valued environmental resources, and it prompts concerns about their scarcity.

But as density increases, local social resources actually increase. High density provides more opportunities for informal contact and assistance because people are more accessible. Density may be positively associated with active informal ties and dependence on a local area for social goods and services. Several writers have suggested such positive effects (Booth, 1976; Freedman, 1975; Hawley, 1972; Jacobs, 1961; Loring, 1956a: 167; Michelson, 1970: 157). The notion of positive effects contradicts the classical view that high density is a mental "overload" and decreases social ties. Urban America is characterized by moderate levels of residential density, and within that range, it is very possible that increasing density enhances social ties.

In summary, new models should include interaction terms to identify the contingent effects of high density. Also, a greater range of dependent variables should be examined-some focusing on positive outcomes, some on negative ones. To accommodate these concerns, we revise the classical negative model and also develop a positive model.

\section{NEGATIVE MODEL (DEPLETION OF ENVIRONMENTAL RESOURCES)}

These are the main features of the revised negative model:

(1) Dependent variables concern reactions to the depletion of environmental resources. For example, items about noise, adequate space, privacy, and control of a space are appropriate. These are highly plausible correlates of density, not attitudes and behaviors which are related to density only at great theoretical distance.

(2) Humans devise numerous mechanisms to cope with high density and buffer its negative effects. Communities adapt by restructuring buildings, parks, and mass transit systems. Individuals adapt through psychological buffers (learning to ignore some environmental stimuli) and through physical ones (architectural 
features of houses and yards). In the Baltimore study, four types of psychological buffers are considered:

(a) Subjective appraisal of population. This variable concerns whether a person feels there are too many, too few, or just the right number of people in an area. Those who feel an area is overpopulated are more likely to be frustrated about environmental resources, especially if they live in high-density areas. Psychologists have long recognized the difference between objective density and the subjective experience of "crowding" (Freedman, 1973; Rapoport, 1975; Stokols, 1976), but sociologists have seldom included subjective measures in their research. Booth (1976) is a recent exception.

(b) Sense of personal control. People who feel in control of their lives rather than controlled by external forces are probably less bothered about environmental problems. They have greater confidence that problems can be resolved and that they can change their own behavior to avoid problems (Proshansky et al., 1970).

(c) Value of privacy. Another type of psychological buffer is the extent to which people value privacy. Those who strongly value privacy may be more frustrated than others about scarce environmental resources (see Altman, 1975).

(d) Exposure to an area. The longer people have lived in a place and the more time they spend there daily, the more likely they are to adjust to unpleasant aspects. (If they continue to be upset, they probably move and become "recent" residents of another place [see Rossi, 1955].) Experience in metropolitan areas and numerous moves during one's lifetime may also aid adjustment to an urban street or neighborhood. Also, having grown up with a large family might help people adjust to household disturbances as adults. In summary, people with high exposure to an area, measured by any of the indicators above, may be less bothered by features which upset a newcomer.

All of these variables act as buffers since they help people in adjusting to a residential area. We are interested in both their additive and interaction effects. Additive effects are as follows: regardless of population density, people with strong buffers 
should be less bothered about environmental resources than people with weak buffers. Interaction effects are as follows: when individual buffers are weak, high density probably causes especially high frustration about an area's resources.

(3) The principal density measure is a ratio of population to area. This is a straightforward indicator and is the one implied in classical statements about density effects.

(4) Several demographic features of an area may be as important as density in influencing environmental responses, but they have been absent in prior research. These are population size, population composition, and recent change in density and size. Wirth (1938) considered size and composition of equal importance to density in influencing urbanites.

(a) Size. Size and density effects have been confounded in the literature, but they are not theoretically equivalent (see Hawley, 1972). The difference between the two should be reflected in statistically independent effects. ${ }^{5}$ Size concerns the total available population of an area. Greater size means more people to take into account in social exchanges. In contrast, density connotes how accessible members of a population are to each other. Greater density entails more chances of face-to-face contact and social stimulation in a daily round. Large population and high density both lead to greater competition for resources of an area and frustration about obtaining them.

(b) Population composition. This variable concerns the degree of heterogeneity among neighbors. Wirth (1938) suggested that high heterogeneity of residents weakens social ties among them. Research on residential segregation, friendship choice, and marriage choice indicates that people do prefer status-similars for intimate ties and close residence (Berscheid and Walster, 1969; Verbrugge, 1977). The more similar co-residents of an area are (or are perceived to be), the more tolerant people may be of environmental scarcities or problems. For example, they may be less bothered about street noise when most of their neighbors are status-similars.

(c) Increases in density and size. Increases in an area's population density and size may temporarily cause frustration and hostility among residents. The larger or more recent the increase, the larger the adverse effects should be. 
Measures of population size, population composition, and change in density and size are included as predictors in the model.

(5) No measures of emotional or physiological stress, which may intervene between the predictors and dependent variables, are included in the model. Thus, like prior research, we do not show how predictor factors are routed to attitude behavior outcomes. But, unlike prior research, we state no assumptions about those processes and leave the issue to other studies.

(6) Residential density is associated with the social, economic, and demographic characteristics of residents. We wish to estimate density effects independent of those characteristics. In the multivariate analysis, principal socioeconomic and demographic items are included as control variables: respondent's sex, age, education, and employment status. No hypotheses are stated for them.

(7) The model is tested in three residential settings: household, street, and neighborhood. These are important sites of social activities common to virtually all city residents. In contrast, many city residents do not have a common workplace or local shopping area. The relationships between the independent variables in the negative model are examined in each of these residential areas.

\section{POSITIVE MODEL}

(INCREASE IN SOCIAL RESOURCES)

The main features of the positive model are as follows:

(1) Dependent variables concern reactions to social resources. Some may be attitudes; others may be behaviors. For example, items about cooperative activities, acquaintance, and social activities during leisure time are appropriate.

(2) Predictors for the negative model are also important for the positive one. Therefore, the independent variables in the positive model are also subjective appraisal of population, sense of personal control, value of privacy, exposure to an area, density, size, population composition, and increases in size and density. The hypotheses for these variables are as follows:

People who feel an area is overpopulated may not exploit its social resources as much as others. People who greatly value 
privacy or have a weak sense of control over life may avoid active social ties in a place. High exposure to an area and prior experience with urban settings may enhance informal ties. The longer people live in a place and the more time they spend there daily, the more likely they are to find friends locally and spend leisure time with them. ${ }^{6}$ The more familiar with highly populated and dense places people are, the more likely it is that they have developed skills in exploiting their social resources.

The larger an area's population, the more possibilities there are for informal social contact. Higher density means that people in an area are more accessible to one another. Both size and density should be positively related to the the number and frequency of local ties. The more similar co-residents are, the more they develop active informal ties. Increases in an area's population size and density provide more local social resources.

All of the variables named are expected to have additive effects (as stated). Some of them may have interaction effects with density, i.e., the effect is especially strong for residents of highdensity areas.

(3) Some additional predictors are included in the positive model. Ample opportunities for social ties outside the neighborhood may reduce local ties. Similarly, if there are many friends or relatives away from home, leisure activities with household members may be reduced. In general, the more alternative opportunities there are, the less active social ties in a given place will be. However, if relatives live on the same street or in the same neighborhood, people may depend on them for social contact. In general, as the number of local relatives increases, local social ties should increase.

\section{HYPOTHESES}

Let us summarize the relationships expected in each model:

For the Negative Model, dependent variables measure frustrations and problems with environmental resources. The following 
predictors are expected to have a positive association with these problems: population density, population size, feeling of overpopulation, value of privacy, amount of recent increase in population size. Variables expected to have a negative association with these frustrations and problems are: exposure to area (length of residence, daily time spent in area, household size when child, childhood and adult residence experience in cities, number of lifetime moves), sense of control, and perceived similarity of co-residents. The negative effects of density will be stronger for people who feel an area is overpopulated, value privacy strongly, have a low sense of personal control, have low exposure to an area, and feel co-residents are not very similar to themselves.

For the Positive Model, dependent variables measure the number and frequency of informal social ties in an area. The following predictors are expected to have a positive association with these ties: population density, population size, exposure to area, sense of control, recent increase in population density, recent increase in population size, perceived similarity of coresidents, and local relatives. Variables expected to be negatively associated with informal ties are: feeling of overpopulation, strong value of privacy, and alternative opportunities. The positive effect of density on social ties should be especially strong for people who are satisfied with an area's population, value privacy little, have higher personal control, have high exposure to an area, and consider co-residents similar to themselves.

Note that most predictors have complementary effects in the two models: The buffers dampen negative aspects of an area and enhance positive ones. Similarity of co-residents also dampens hostile reactions to a local environment and encourages social ties there. Feelings of overpopulation increase aggravations and reduce social ties in a place.

But the hypotheses for population density and size, and their increase, are radically different. We hypothesize that high density and size increase both environmental frustrations and social integration. The claim is that increasing density and size have dual effects-some unpleasant, some pleasant. 


\section{DATA SOURCE}

In spring 1976, a survey was conducted in the Baltimore metropolitan area to examine the hypotheses above. A multistage, stratified sample of white, owner-occupied households was selected. In each sampled household, the household head or spouse-of-head was interviewed. The completed sample size was $237 .{ }^{7}$

The study was restricted to homeowners since they probably have a greater emotional investment in their home and neighborhood than other people (see Wellman and Whitaker, 1974). They may therefore be more sensitive to density effects, responding to discomforts more strongly and utilizing social resources more readily than apartment dwellers. This gives the hypotheses better chances of being confirmed in a homeowner sample than one including both homeowners and apartment dwellers. ${ }^{8}$

Variables for the Negative and Positive Models were obtained for three settings: the respondent's household, street, and neighborhood. The household is defined according to the U.S. Bureau of the Census (1976). ${ }^{9}$ The street is defined as the block face which contains the respondent's home plus the block face opposite it. The respondent identified his/her neighborhood by drawing its boundaries on a map. In the questionnaire, the three areas are usually distinct, i.e., questions about the neighborhood explicitly exclude the street.

\section{PROCEDURE}

In preliminary analysis, cross tabulations of independent with dependent variables were examined for two purposes: to obtain a clear view of the pattern and strength of bivariate relationships, and to select variables for multivariate analysis. The majority of these tables supported the hypotheses just stated (see Verbrugge and Taylor, 1977). Variables were retained for multivariate analysis if they showed persistently linear, significant relationships in the cross-tabulations. 
Multiple regression analysis of selected predictors and dependent variables was performed. Two types of statistical models are estimated, differing in how interaction effects are constructed. Both models have additive terms for density $\left(X_{1}\right)$ and other predictors $\left(X_{2}, \ldots, X_{M}\right)$. Model I has interaction terms of the form $D_{i} X_{1}$ where $X_{1}$ is population density and $D_{i}$ are dummy variables for categories of another predictory $\left(X_{m}\right)$. Model II has interaction terms of the form $X_{m} X_{1}$ where $X_{1}$ is population density and $X_{m}$ is one of the other predictors. For the additive terms, the variables $X_{2}, \ldots, X_{M}$ are assumed to be interval-scaled. (For Model I, scores for an $X_{m}$ are pooled to form two or three categories and then the associated dummy variables $\mathrm{D}_{\mathrm{i}} \mathrm{X}_{1}$ are created.) Significant effects for the $X_{m} X_{1}$ are more difficult to interpret than for $D_{i} X_{1}$ terms, but they have an extra advantage of reflecting nonlinear effects in a parsimonious manner.

The general form of the two models is:

Model I: $\hat{\mathrm{Y}}=\mathrm{f}\left[\mathrm{X}_{1}, \mathrm{X}_{2}, \ldots, \mathrm{X}_{\mathrm{M}}, \mathrm{D}_{2 \mathrm{i}} \mathrm{X}_{1}, \mathrm{D}_{3 \mathrm{i}} \mathrm{X}_{1}, \ldots\right]$ where $\mathrm{X}_{1}$ is population density; $X_{2}, \ldots, X_{M}$ are other predictor items; $D_{2 i} X_{1}$ are interaction terms for $X_{2}$ with density; and so forth.

Model II: $\hat{\mathrm{Y}}=\mathrm{f}\left[\mathrm{X}_{1}, \mathrm{X}_{2}, \ldots, \mathrm{X}_{\mathrm{M}}, \mathrm{X}_{2} \mathrm{X}_{1}, \mathrm{X}_{3} \mathrm{X}_{1}, \ldots\right.$. $]$ with variables defined as for Model I. ${ }^{10}$

Predictors are incorporated in a hierarchical fashion. First, the social and demographic variables are entered; then all other $\mathbf{X}_{\mathbf{m}}$ terms; and finally, interaction terms. These three sets are referred to as control, additive, and interaction effects. The purpose of such ordering is to eliminate at the outset all correlation due to socioeconomic and demographic variables, then to examine the net effects of theoretical interest. This is a decidedly conservative approach to finding density (and other $X_{i}$ ) effects. The procedure allows only density effects which are wholly independent of additive ones, since they enter the regression after the $X_{i}$ terms. ${ }^{11}$ Stepwise procedures are used within each of the three sets (i.e., a variable is included only if it meets specified statistical criteria, and these criteria are checked after each addition of a variable).

Models I and II were estimated twice, first with all predictors, then with a reduced set of them. For the reduced models, only 
predictors whose coefficients were statistically different from zero $(P \leqslant .05)$ in the full model were retained. ${ }^{12}$ Pairwise correlation matrices were the input for all regressions. The case base is 221 , the smallest base for pairwise correlations among the variables.

\section{VARIABLES FOR REGRESSIONS}

\section{INDEPENDENT VARIABLES}

Table 1 shows the population density and size variables used, with descriptive statistics. Subjective appraisal of population was determined by asking respondents: "How do you feel about the number of people living [in your household/on your street/in your neighborhood]? Are there far too many people, a few too many, just the right number, not quite enought, or far too few?" In their answers, respondents might consider population size, or density, or both. Three Rotter items measure sense of personal control (Rotter, 1966). Three value of privacy items are taken from a prior study on density effects (Baron et al., 1976). Exposure to the three areas is measured by (a) residence length, (b) usual number of waking hours spent at home, (c) type of place lived in during most of childhood (large city, suburb, etc.), (d) type of place lived in during most of adulthood, (e) number of lifetime moves, and (f) usual household size (number of members) when $\mathrm{R}$ was growing up. For the household, population composition is measured by the proportion of household members who are under 18 years old. For the street and neighborhood, the proportion of neighborhood (including street) residents who are in R's age group is used. Changes in density and in population size within the past year were estimated for all three areas. Measures of alternative opportunities and local relatives are respondent reports of (a) the number of close friends living on their street, neighborhood, and within an hour's travel time and (b) the number of adult relatives in these three areas. ${ }^{13}$ Control variables used are sex, age at last birthday, years of school completed, and employment status (employed or not employed). 
TABLE 1

Descriptive Statistics for Density and Size Variables, Baltimore 1976

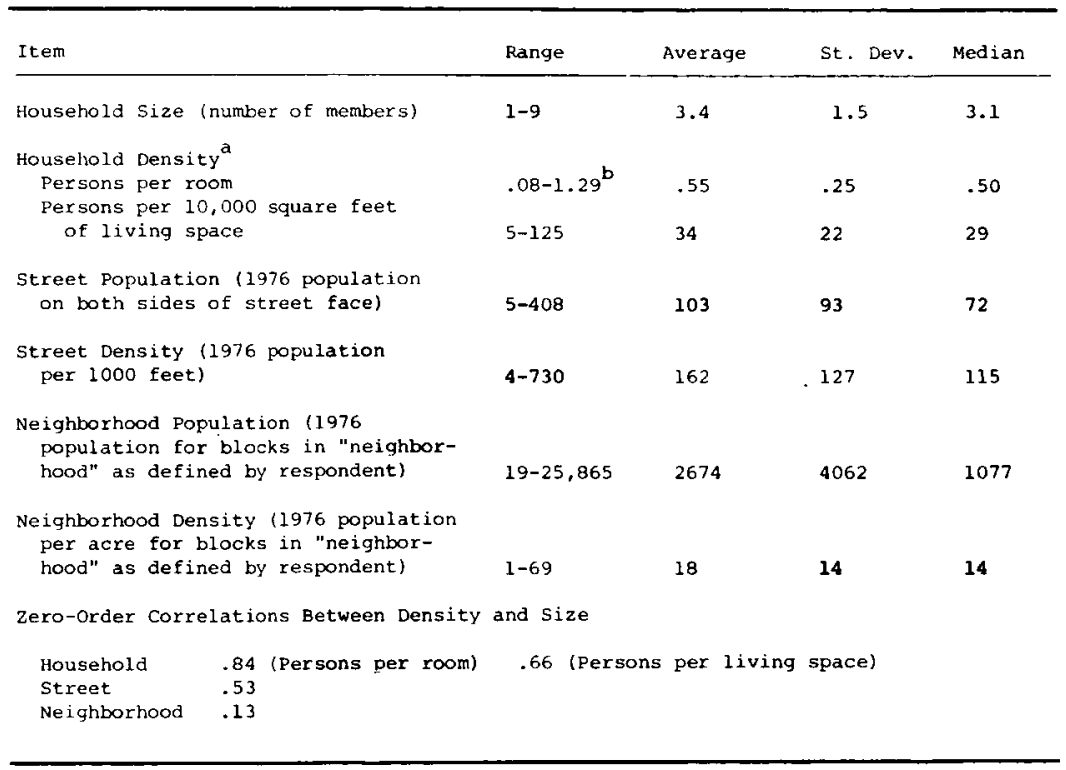

a. Persons per $10,000 \mathrm{sq}$. $\mathrm{ft}$. of living space is available for only 185 respondents. All other density and size measures are available for the full sample $(n=237)$. To exploit the full sample data, cross tabulations use the persons-per-room density measure. In multivariate analysis, persons-per-living-space is the household density measure.

b. None percent of all study households have a persons-per-room score greater than 1.00 .

\section{DEPENDENT VARIABLES}

For the Negative Model, dependent variables measure perceptions of local environments and dissatisfaction with them. The variables are:

Household. (1) How often there are conflicts among household members about using the same space in the house. (2) If $R$ lacks a private place in the house. (3) How dissatisfied $R$ is with the amount of privacy at home. (4) How often the house is noisy because of things other members are doing. (5) How often $R$ is bothered by household noise.

Street. (1) How often the street is noisy. (2) How often $R$ is bothered by street noise. 
Neighborhood. (1) If there are neighborhood places other than neighborhood stores, businesses, and parks where $R$ is bothered by too many people. (2) Number of neighborhood places where $R$ ever feels there are too many people.

For the Positive Model, dependent variables measure perceptions of social resources in local environments and use of those resources. The variables are:

Household. (1) How often household members help R with chores. (2) If a household member would be the first source of help when $R$ is ill. (3) If a household member would be the first source to talk with about a personal problem. (4) When $R$ spends leisure time with other people, if that leisure time is spent mostly with household members.

Street. (1) Number of adult street residents known by face and name. (2) Percentage of adult street residents known. (3) Percentage of R's close friends who live on the street. (4) Number of activities ever done with street residents. (Sum of answers to 7 items of this form: "Have you ever done [activity] with someone living on your street?")

Neighborhood. (1) Number of adult neighbors known by face and name. (2) If neighbor would be the first source of help when $R$ is ill. (3) If neighbor would be the first source to talk with about a personal problem. (4) Percent of R's close friends who are neighbors. (5) Number of activities ever done with neighbors. (cf. Item 4 for Street), (6) When R spends leisure time with other people, if that leisure time is spent mostly with neighbors.

\section{RESULTS}

Altogether, four equations were estimated for every dependent variable: a full model and a reduced one for Model I, and the same for Model II. Detailed results for all regressions are not presented 
here. We shall summarize the results, first stating the success of the Negative and Postive Models, then the relative importance of predictor groups (control, additive, interaction), and finally the overall effects of specific predictors. Results for Models I and II are so similar that no distinction needs to be made in the discussion. Table 2 presents summary statistics for Model I.

\section{SUCCESS OF THE NEGA TIVE MODEL}

The Negative Model is most strongly supported in the household. Compared to the other two settings, the $\mathbf{R}^{2}$ are usually larger for the household; more predictors are retained in the reduced models; and more of the significant coefficients have the hypothesized sign.

Striking results for each area are as follows:

Household. Considering all regressions, these additive effects stand out: Large household size tends to increase frustrations at home, but high household density seldom does so. Apparently the number of people, not thier proximity, causes dissatisfaction. As expected, people who think the household has too many members are more bothered there than are others. A strong sense of personal control reduces frustrations at home, but a high proportion of children and recent increases in household size aggravate them. One interaction effect is persistently important: High household density is especially bothersome to recent residents and much less so for long-term residents.

The Negative Model is most strongly supported by the "noise" variables (perceived frequently of household noise and how often noise bothers $\mathbf{R})$. These discomforts tend to increase with larger household size, the feeling there are too many members, short residence length, low sense of personal control, need for privacy, recent increases in household size, and a high proportion of children. High density and recent increases in density do not increase these discomforts. Some people are especially sensitive to noise in high-density households: those who value privacy greatly, who are recent residents, and who are not home often. 
Street. The Negative Model yields weaker results for the street area. Only the "noise" variables show significant results: People living on high-density streets or on streets with recent increase in

TABLE 2

Overall $\mathbf{R}^{2}$ and Increments in $\mathbf{R}^{2}$ for Full and Reduced Model I, Baltimore 1976

\begin{tabular}{|c|c|c|c|c|c|}
\hline \multirow[b]{2}{*}{ NEGATIVE MODEL } & \multicolumn{4}{|c|}{ Household } & \multirow[b]{2}{*}{$\begin{array}{l}\text { Bothered } \\
\text { by } \\
\text { noise }\end{array}$} \\
\hline & $\begin{array}{l}\text { Space } \\
\text { con- } \\
\text { flict }\end{array}$ & $\begin{array}{l}\text { Lack } \\
\text { private } \\
\text { space }\end{array}$ & $\begin{array}{l}\text { Dissat. } \\
\text { with } \\
\text { privacy }\end{array}$ & $\begin{array}{l}\text { How } \\
\text { often } \\
\text { noisy }\end{array}$ & \\
\hline \multicolumn{6}{|l|}{ Fuß̧l Model } \\
\hline $\mathrm{R}^{2}$ & $.261 *$ & $.189 *$ & $.297^{\star}$ & $.535 *$ & $.579 *$ \\
\hline $\mathrm{df}$ & 193 & 193 & 194 & 193 & 193 \\
\hline \multicolumn{6}{|l|}{ Requced Model } \\
\hline $\mathrm{R}^{2}$ & $.214^{*}$ & $.161 *$ & $.269^{*}$ & $.50{ }^{\star}$ & $.574 *$ \\
\hline df & 205 & 206 & 203 & 204 & 196 \\
\hline \multicolumn{6}{|l|}{ Increments } \\
\hline Control & $.055^{\star}$ & $.037^{*}$ & $.046^{\star}$ & $.159 *$ & $.123^{\star}$ \\
\hline Additive & $.129 *$ & $.094 *$ & $.177^{*}$ & $.345^{\star}$ & $.387^{\star}$ \\
\hline \multirow[t]{3}{*}{ Interactions } & .030 & $.030^{\star}$ & $.046^{*}$ & .004 & $.064^{*}$ \\
\hline & \multicolumn{5}{|c|}{ Street } \\
\hline & $\begin{array}{l}\text { How } \\
\text { often } \\
\text { noisy }\end{array}$ & $\begin{array}{l}\text { Bothered } \\
\text { by } \\
\text { noise }\end{array}$ & & & \\
\hline \multicolumn{6}{|l|}{ Full Model } \\
\hline $\mathrm{R}^{2}$ & .166 & .154 & & & \\
\hline $\mathrm{df}$ & 189 & 190 & & & \\
\hline \multicolumn{6}{|l|}{ Requced Model } \\
\hline & $.092 \star$ & $.065 *$ & & & \\
\hline df & 214 & 214 & & & \\
\hline \multicolumn{6}{|l|}{ Increments } \\
\hline Control & $.034^{\star}$ & .024 & & & \\
\hline Additive & $.059 *$ & $.041 *$ & & & \\
\hline \multirow[t]{3}{*}{ Interactions } & - & - & & & \\
\hline & \multicolumn{5}{|c|}{ Neighborhood } \\
\hline & $\begin{array}{l}\text { If other } \\
\text { place } \\
\text { too many }\end{array}$ & $\begin{array}{l}\text { Total pl } \\
\text { too many } \\
\text { people }\end{array}$ & & & \\
\hline \multicolumn{6}{|l|}{ Full Model } \\
\hline $\mathrm{R}^{2}$ & $.231^{\star}$ & $.240^{\star}$ & & & \\
\hline $8 \mathrm{f}$ & 190 & 192 & & & \\
\hline \multicolumn{6}{|l|}{ Requced Model } \\
\hline $\mathrm{R}^{2}$ & $.161 *$ & $.215^{*}$ & & & \\
\hline df & 213 & 204 & & & \\
\hline \multicolumn{6}{|l|}{ Increments } \\
\hline Control & $.126^{\star}$ & $.037 \star$ & & & \\
\hline Additive & $.032 *$ & $.076^{\star}$ & & & \\
\hline Interactions & .003 & $.101 *$ & & & \\
\hline
\end{tabular}


TABLE 2 (Continued)

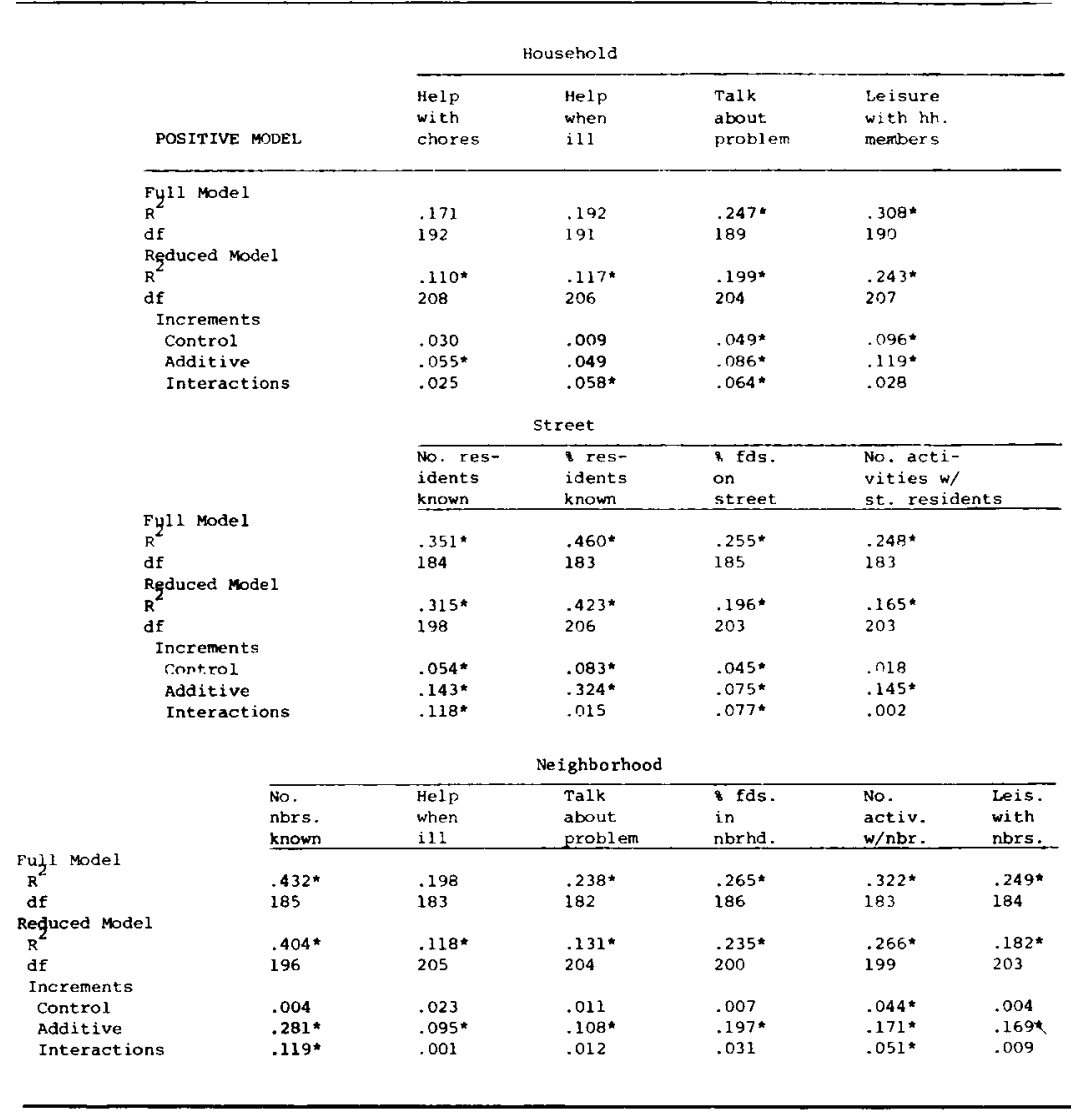

* Significant at $P \leqslant .05$ (two-tailed test).

- No variables for this group are included in the education.

density report more frequent street noise and are more bothered by it than are other people.

Neighborhood. The Negative Model fares poorly for the neighborhood area. One additive effect merits note: Respondents who feel the neighborhood has too many people tend to view local facilities as crowded, compared to respondents who don't perceive overpopulation. 


\section{SUCCESS OF THE POSITIVE MODEL}

The Positive Model applies best to the street and neighborhood areas. Results for each area are:

Household. Considering all household regressions, these additive effects stand out: People who strongly value privacy or who live in households with a proportion of children are least dependent on co-residents for help and spend the least leisure time with them. Three factors are associated with high use of social opportunities in dense households: high daily exposure there, a strong sense of control over life, and satisfaction with household size. (Note that the latter are interaction effects, not additive ones.)

Street. The Positive Model is more applicable to the street as an area. Additive effects are strongest for age composition and population size: The more similar $R$ is in age to street residents, the more active R's ties are with them. Heavily populated streets also encourage the number of social ties, although they do reduce the percentage of street residents known. Long residence on the street usually encourages local ties. The Positive Model is most stongly supported by acquaintance variables (number of street residents known, and percentage of street population known.)

Neighborhood. The Positive Model is supported well for the neighborhood area. Alternative opportunities and local relatives are often significant predictors: Local social ties increase if some of R's neighbors are kin. Neighborhood social ties decrease when $\mathbf{R}$ has numerous friends living outside the neighborhood or if R's household is large. Two other additive effects stand out: Feelings that the neighborhood is overpopulated tend to reduce local ties. But high age-similarity with neighbors increases ties. Interaction effects which support our hypotheses involve residence length and subjective appraisal; i.e., long-term residents of dense neighborhoods and people who like dense areas are more likely to exploit social resources there.

The model receives most support for these three variables: number of neighbors known, number of activities done with 
neighbors, and percentage of close friends who are neighbors. All of these are increased by large neighborhood population and by the presence of relatives there.

\section{GROUPS OF PREDICTORS}

Socioeconomic and demographic controls have significant $\mathbf{R}^{2}$ increments in only $61 \%(28 / 46)$ of the equations, despite the fact that they enter the regression equations first. Most of the significant increments occur in the Negative Model. The group of additive predictors usually produce a significant increment (in 42/46 equations). This means that an area's demographic features and an individual's adaptive skills are important predictors of reactions to residential places. The group of interaction terms is significant in about half the regressions (19/42). Interactions are most significant for the household area $(9 / 17)$, suggesting that sensitivity to high household density can vary by personality and exposure.

\section{EFFECTS OF SPECIFIC PREDICTORS}

The most surprising result is that population size is a more important predictor than population density. More regression coefficients for population size are significant and $90 \%$ of them (18 of 20 significant coefficients) are in the hypothesized direction, compared to $62 \%(8 / 13)$ for density. In other words, size effects are more consistent with our theory in every setting than are density effects. Large household size tends to increase discomforts there, but it also increases social ties with household members. Large street or neighborhood population encourages local ties.

Subjective appraisal of population in an area is also more significant than density. People who feel an area is overpopulated are more likely to complain of its scarce environmental resources and fail to exploit its rich social ones. This is especially true in the 
household. Overall, $94 \%(15 / 16)$ of the significant coefficients for subjective appraisal are in the hypothesized direction.

After size and subjective appraisal, population composition is the most significant predictor. It has numerous significant coefficients, and virtually all of them (17/18) are in the hypothesized direction. As the proportion of children at home increases, frustrations about the home environment rise and social involvement there diminishes. Age-similarity with street and neighborhood residents dampens one's perception of discomforts and increases social ties there.

Of the remaining buffer variables, sense-of-control supports the hypotheses most often. It is mainly important in the household: People with a strong sense of personal control are less bothered by household disturbances and more able to recruit help at home than are other people. Several buffer variables (residence length, daily exposure, need for privacy) are important in specific situations. The other buffers (lifetime moves, metropolitan experience, household size during childhood) rarely have significant effects.

Recent increases in size and density have some negative effects: People become more frustrated about privacy and noise when household size or street density increases. Positive effects of this increase are apparently delayed rather than totally absent, since we already have found that large populations encourage social ties.

There is some evidence that friends and family compete for a person's leisure time and attention. The larger a person's household and the more friends living outside the neighborhood, the less he or she relies on street and neighborhood residents for help and social activity. But local relatives are attractive companions, and their presence in the neighborhood increases a person's social ties there.

Interaction terms which support the hypotheses most often are exposure variables (residence length, daily exposure) and subjective appraisal of population. Thus, long exposure to a highdensity area and satisfaction with the number of people there blunt environmental discomforts and also encourage social ties in the area. 


\section{DISCUSSION AND CONCLUSIONS}

The results show the merits of studying density effects within a broad theory of how people use a residential area's environmental and social resources. What are the density effects found in the Baltimore study? High residential density has some effects on urbanites' attitudes and behavior. This occurs most often in their household, where the effects are mostly "negative" (Negative Model). "Positive" effects of high density are less common and occur mainly in street and neighborhood areas. A few interaction effects with density appear, occurring most often in the household; this means that individuals with adaptive skills are less sensitive to unpleasant aspects of high household density and more responsive to pleasant ones.

The study's truly novel and important results concern: (1) population size and other areal characteristics, (2) personality characteristics that serve as buffers, (3) dual effects, and (4) different residential areas.

(1) Wirth (1938) believed that population size, density, and heterogeneity have strong influences on urban dwellers. The Baltimore study confirms this; all three are important predictors of urbanites' social ties and attitudes about their local environments. But density has much weaker effects than size and population composition; population size especially overshadows density as a predictor. This suggests that researchers who focus solely on density are "wide of the mark," missing some important areal charcteristics.

People's feelings about an area's population are also important. Subjective appraisal of population is a better predictor of attitudes and behaviors in the Negative and Positive Models than objective density is.

In summary, how accessible residents are to each other (i.e., density) has much less impact on environmental attitudes and social ties than how many residents there are, what their social and demographic characteristics are, and what their subjective feelings about local population size and density are. We are especially intrigued by the population size results. Experimental psychologists have given ample attention to the effects of group 
size on members' attitudes and task performance. The Baltimore study indicates that size makes a difference for real-life groups, too.

(2) Some psychological characteristics prevent people from being aggravated by nuisances at home and in local areas, and also help them to use social opportunities there. High sense of personal control is especially helpful; sometimes low need for privacy and long exposure to a place help. In some cases, these personality characteristics are very beneficial, and they enhance a person's ability to adjust to high-density areas. The presence of these buffers and their interaction with density means that no simple model of density effects is adequate. People find ways to blunt negative features of a place and to exploit positive ones. Fuller understanding of these buffers is left to other research.

(3) High population density and large population size have "dual effects"-both negative and positive consequences. They not only increase discomfort in a place but also increase social ties there. The classical model (of negative effects) is only half the real-life story. As Jacobs (1961) suggests, residential areas with many people or people living close to each other can have social benefits.

(4) Support for the Negative and Positive Models varies across types of residential settings. The Negative Model explains environmental frustrations best in the household. High density and large family size cause more frustrations there than in the street or neighborhood. But the Positive Model explains social ties best in the street and neighborhood areas. High density and large population size tend to encourage more social contacts there than at home. We do not know why these variations occur. Maybe bothersome features at home cannot easily be ignored, whereas nuisances on the street or neighborhood can be avoided or "tuned out." There is no obvious answer and we welcome the thoughts and research of other investigators. The important contribution made by the Baltimore study is to demonstrate (within a single data set) that the effects of density and size do vary in different types of residential areas. 
In conclusion, residential density has its largest effects in the household. People with certain adaptive skills are able to blunt some negative effects of high density, mainly within the household. Thus the site where negative density effects are strongest is also where adaptive skills prove most beneficial. But population density effects of any kind are meager compared to those of population size. Simply put, living in Baltimore (a large place) versus Haggerstown (a small place) may make more difference than living in a neighborhood of row houses (a dense area) versus separate houses (a less dense area).

\section{NOTES}

1. Durkheim (1960) also considered density effects, but from a macrosociological perspective. He proposed that high density in cities fosters the specialization and division of labor. Durkheim's thoughts on density effects have strongly influenced American sociology, especially urban ecology.

2. Psychologists who study density effects have relied on these sociological models and also models of animal behavior. Psychological research focuses on how density influences interpersonal behavior (especially aggression) and task performance. Numerous variations in settings, subject characteristics, duration of exposure, tasks, and social interaction have been tried in experiments or observed in natural settings (see Freedman et al., 1971; Loo, 1972; Ross et al., 1973; Sherrod, 1974). Strong negative effects are seldom found. For a review of psychological studies, see Freedman (1975).

3. See Carnahan and Galle (1973), Choldin (1978), and Freedman (1975) for reviews. See Booth (1976) for a comprehensive study.

An exception to the latter is Booth's (1976) study.

5. The confusion may arise because size and density can be statistically equivalent in one case - when areas of fixes spatial size are studied. Population size and density are then periectly correlated. When areas are chosen on the basis of political or social boundaries, size and density are not equivalent. Their correlation is still positively correlated but not perfectly.

Sociologists are not alone in ignoring size effects in density studies. Psychology has a large literature on group size effects (O'Dell, 1968; Thomas and Fink, 1963; Willems, 1964), but experimental studies of density effects have ignored group size as a variable independent of density.

6. This association could be a spurious one if another factor causes both residential stability and local integration.

7. Sampling details are stated in Verbrugge and Taylor (1977).

8. A possible criticism of the restriction to homeowners is that the range of street and neighborhood densities is reduced, compared to a sample including apartment dwellers. 
Therefore, the study may not capture linear or nonlinear effects of population density that actually exist over the full span of densities experienced by urban Americans. We do not believe this is a serious deficiency: If those effects are weaker for apartment dwellers than homeowners, a wider span of densities would not reveal clearer or stronger relationships than the narrow span. We hope this claim can be tested in other research.

9. "A household includes the related family members and all the unrelated persons, if any ... who share [a] housing urit. A person living alone in a housing unit, or a group of unrelated persons sharing a housing unit as partners, is also counted as a household" (U.S. Bureau of the Census, 1976: 90).

10. Actually, the additive density term $X$, had to be eliminated from Model II, due to high multicollinearity with the interaction terms. The estimated form therefore excludes the $X_{1}$ term.

11. The sequential entry of additive and interaction terms is discussed and justified in Allison (1977).

12. The rules for inclusion are actually more complex: (1) Always include the control variables education, sex, and age. (Employment status showed too few significant effects to merit keeping.) (2) Always include density and size. (3) Include any additive or interaction terms which have significant effects. Include their associated interaction (or additive) term(s), whether these are significant or not. (4) For any significant interaction term of the $\mathrm{DiX}_{1}$ form, include all interaction terms built from the original $\mathrm{X}$ variable. (5) An X (additive) effect was included for all dependent variables if it had significant effects in most of the full models.

13. An example of how these variables are used: In street equations, the number of close friends not living there and number of relatives who do live there are included as predictors.

\section{REFERENCES}

ALLISON, P. D. (1977) "Testing for interaction in multiple regression." Amer. J. of Sociology 83, 1: 144-153.

ALTMAN, I. (1975) The Environment and Social Behavior. Belmont, CA: Wadsworth. BALDASSARE, M. (1975) "The effects of density on social behavior and attitudes." Amer. Behavioral Scientist 18: 815-825.

BARON, R., D. R. MANDEL, C. A. ADAMS, and L. M. GRIFFEN (1976) "Effects of social density in university residential environments." J. of Personality and Social Psychology 34: 434-446.

BERSCHEID, E. and E. H. WALSTER (1969) Interpersonal Attraction. Reading, MA: Addison-Wesley.

BOOTH, A. (1976) Urban Crowding and Its Consequences. New York: Praeger.

CARNAHAN, D. L. and O. R. GALLE (1973) "Needed research in the study of population density." Report for the Southern Regional Demographic Group, Oak Ridge, Tennessee.

CHOLDIN, H. M. (1978) "Urban density and parhology," pp. 91-113 in Volume 4 of R. H. Turner (ed.) Annual Review of Sociology. Palo Alto, CA: Annual Reviews, Inc. 
and D. W. RONCEK (1976) "Density, population potential and pathology: a block-level analysis." Public Data Use 4: 19-30.

DAY, A. T. and L. H. DAY (1973) "Cross-national comparison of population density." Science 181 (September 14): 1016-1023.

DURKHEIM, E. (1960) On the Division of Labor in Society (G. Simpson, trans.) New York: Macmillan. (Originally published in 1893.)

FELSON, M. and M. SOLAUN (1975) "The fertility-inhibiting effect of crowded apartment living in a tight housing market." Amer. J. of Sociology 80: 1410-1427.

FISCHER, C. S. (1972) "Urbanism as a way of life: a review and an agenda." Soc. Methods and Research 1: 187-242.

FREEDMAN, J. L. (1975) Crowding and Behavior. San Francisco: Freeman. (1973) "Conceptualization of crowding," pp. 499-509 in C. F. West off and R. Park, Jr. (eds.) Population Distribution and Policy. Volume 5, Reports for the Commission on Population Growth and the American Future. Washington, DC: Government Printing Office.

- - S. KLEVANSKY, and P. EHRLICH (1971) "The effect of crowding on human task performance." J. of Applied Social Psychology 1: 7-25.

GALLE, O. R., W. R. GOVE, and J. M. McPHERSON (1972) "Population density and pathology: what are the relations for man?" Science 176: 23-30.

HAWLEY, A. H. (1972) "Population density and the city." Demography 9, 4: 521-529.

JACOBS, J. (1961) The Death and Life of Great American Cities. New York: Random House.

LOO, C. M. (1972) "The effects of spatial density on the social behavior of children." J. of Applied Social Psychology 2: 372-381.

LORING, W. C. (1956a) "Housing and social organization." Social Problems 3: 167-173. (1956b) "Housing characteristics and social disorganization." J. of Social Problems 3: 160-168.

MICHELSON, W. (1970) Man and His Urban Environment: A Sociological Approach. Reading, MA: Addison-Wesley.

MILGRAM, S. (1970) "The experience of living in cities." Science 167: 1461-1468.

MITCHELL, R. W. (1971) "Some social implications of high density housing." Amer. Soc. Rev. 36: 18-29.

O'DELL, J. W. (1968) "Group size and emotional interaction." J. of Personality and Social Psychology 8: 75-78.

PROSHANSKY, H. M., W. H. ITTELSON, and L. G. RIVLIN (1970) "Freedom of choice and behavior in a physical setting," pp. 173-183 in Proshansky et al. (eds.) Environmental Psychology. New York: Holt, Rinehart \& Winston.

RAPOPORT, A. (1975) "Toward a redefinition of density." Environment and Behavior 7: $133-158$.

ROSOW, I. (1967) Social Integration of the Aged. New York: Macmillan.

ROSS, M., B. LAYTON, B. ERICKSON, and J. SCHOPLER (1973) "Affect, facial regard, and reactions to crowding." J. of Personality and Social Psychology 28: 68-76.

ROSSI, P. (1979) Why Families Move: A Study in the Social Psychology of Urban Residential Mobility. Beverly Hills, CA: Sage.

ROTTER, J. (1966) "Generalized expectancies for internal versus external control of reinforcement." Psych. Monographs 80: 1-28.

SCHMITT, R. (1966) "Density, health, and social disorganization." J. of the Amer. Institute of Planners 32: 38-70. 
SHERROD, D. R. (1974) "Crowding, perceived control, and behavioral aftereffects." J. of Applied Social Psychology 4: 141-186.

SIMMEL, G. (1971) "The metropolis and mental life," pp. 324-339 in D. L. Levine (ed.) On Individuality and Social Forms. Chicago: Univ. of Chicago Press. (Originally published in 1903.)

STOKOLS, D. (1976) "The experience of crowding in primary and secondary environments." Environment and Behavior 8, 1: 49-86.

THOMAS, E. J. and C. F. FINK (1963) "Effects of group size." Psych. Bull. 60: 371-384.

U.S. Bureau of the Census (1976) Household and Family Characteristics; March 1975. Current Population Reports, Series P-20, No. 291. Washington, DC: Government Printing Office.

VERBRUGGE, L. M. (1977) "The structure of adult friendship choices." Social Forces, 56, 2: 576-597.

-_- and R. B. TAYLOR (1977) "Consequences of population density in Baltimore." Presented at the American Sociological Association meetings, Chicago.

WELLMAN, B. and M. WHITAKER (1974) High-Rise, Low-Rise: The Effects of High Density Living. Discussion Paper B.74.29. Ottawa: Ministry of State, Urban Affairs.

WILLEMS, E. P. (1964) "Review of research," pp. 29-37 in R. G. Barker and P. V. Gump (eds.) Big School, Small School: High School Size and Student Behavior. Stanford, CA: Stanford Univ. Press.

WINSBOROUGH, H. H. (1965) "The consequences of high population density." Law and Contemporary Problems 31: 120-126.

WIRTH, L. (1938) "Urbanism as a way of life." Amer. J. of Sociology 44: 1-24.

Lois M. Verbrugge is a social demographer, currently Assistant Professor in the Department of Biostatistics, University of Michigan. Her graduate degrees are Ph.D. and M.A. (Sociology, University of Michigan, 1974, 1970) and M.P.H. (Master of Public Health; University of Michigan, 1969). The density study was conducted while Verbrugge was a faculty member of the Department of Social Relations, Johns Hopkins University. Her other research interests are sex differences in morbidity and mortality, urban social networks, and marital differentials in health.

Ralph B. Taylor is an environmental psychologist, currently Assistant Professor in the Department of Psychology, Virginia Polytechnic Institute. His graduate degree is Ph. D. (Psychology, Johns Hopkins University, 1977). Taylor was researchassistant for hte study reported in this article. His main research interest is consequences of density and group size on environmental perceptions and social attitudes. 